\title{
An ab initio study of the reaction of atomic hydrogen with sulfur dioxide
}

\author{
Derk Binns and Paul Marshall \\ Department of Chemistry, University of North Texas, PO Box 5068, Denton, Texas 76203
}

(Received 23 May 1991; accepted 25 June 1991)

\begin{abstract}
The potential energy surface for $\mathrm{H}\left(1^{2} S\right)+\mathrm{SO}_{2}$ has been investigated computationally in order to study the catalytic removal of atomic hydrogen in flames by sulfur dioxide. HF/3$21 \mathrm{G}\left({ }^{*}\right)$ and MP2/3-21G(*) levels of theory were employed to locate stationary points, which were then characterized by calculation of the vibrational frequencies. Some geometries were also optimized with the $6-31 \mathrm{G}^{*}$ basis set. Two adducts $\mathrm{HOSO}$ and $\mathrm{HSO}_{2}$, with $\mathrm{H}$ bonded to $\mathrm{O}$ or $\mathrm{S}$, respectively, were studied. Energies were estimated at the optimized geometries using spin-projected MP4/6-31G* calculations, which show that planar cis HOSO is more stable than $C_{s} \mathrm{HSO}_{2}$. An $\mathrm{H}-\mathrm{OSO}$ bond energy of $109 \mathrm{~kJ} \mathrm{~mol}^{-1}$ is predicted. By contrast $\mathrm{HSO}_{2}$ is predicted to be $25 \mathrm{~kJ} \mathrm{~mol}^{-1}$ endothermic with respect to $\mathrm{H}+\mathrm{SO}_{2}$, and is insufficiently stable to be significant in combustion chemistry. Transition states were located and the information used to derive the kinetics of $\mathrm{H}+\mathrm{SO}_{2}+\mathrm{Ar} \rightleftarrows \mathrm{HOSO}+\mathrm{Ar}$ from 298 to $2000 \mathrm{~K}$. An unusually large energy barrier to recombination, of about $95 \mathrm{~kJ} \mathrm{~mol}^{-1}$ relative to $\mathrm{H}+\mathrm{SO}_{2}$, is proposed. The results are compared with available kinetic measurements. Other potential decomposition channels for $\mathrm{HOSO}$, to $\mathrm{SO}+\mathrm{OH}$ and isomerization to $\mathrm{HSO}_{2}$, were also analyzed.
\end{abstract}

\section{INTRODUCTION}

Addition of sulfur dioxide to flames reduces the concentration of atomic hydrogen, a phenomenon which is attributed to catalysis of $\mathrm{H}$-atom recombination via formation of an adduct between $\mathrm{H}$ and $\mathrm{SO}_{2},{ }^{1-6}$

$$
\begin{aligned}
& \mathrm{H}+\mathrm{SO}_{2}(+\mathrm{M}) \rightarrow \mathrm{SO}_{2} \cdot \mathrm{H}(+\mathrm{M}), \\
& \mathrm{SO}_{2} \cdot \mathrm{H}+\mathrm{H} \rightarrow \mathrm{SO}_{2}+\mathrm{H}_{2} .
\end{aligned}
$$

Provided reaction (1) maintains an equilibrium $\left[\mathrm{SO}_{2} \cdot \mathrm{H}\right]$, the overall loss of $\mathrm{H}$ atoms will be second order in [H]. Experimental data from $\mathrm{SO}_{2}$-seeded flames thus yields the product $K_{1} k_{2}$, where $K_{1}$ is the equilibrium constant for reaction (1) and $k_{2}$ is the rate constant for reaction (2)., $3,4,6$ Kallend estimated that the $\mathrm{SO}_{2}-\mathrm{H}$ bond energy $D_{0}$ is at least $200 \mathrm{~kJ} \mathrm{~mol}^{-1}$, and probably between 210 and 250 $\mathrm{kJ} \mathrm{mol}^{-1}$, based on observations of emission from $\mathrm{Na}\left(3^{2} P\right)$ believed to be excited by reaction (1) with $\mathrm{M}=\mathrm{Na} .{ }^{2}$ Later workers employed $D_{0}=264 \mathrm{~kJ} \mathrm{~mol}^{-1}$.,4

A potential interference in combustion studies of the elementary reaction (1) is the complex network of reactions which interconverts the many reactive intermediates present in a flame. One experiment designed to isolate reaction (1) from other processes set an upper limit to $k_{1}$ of $<1.5 \times 10^{-33} \mathrm{~cm}^{6}$ molecule ${ }^{-2} \mathrm{~s}^{-1}$ at room temperature. ${ }^{7}$ This upper limit, coupled with flame measurements, implies an unusual positive activation energy for this recombination reaction of at least $12 \mathrm{~kJ} \mathrm{~mol}^{-1}$ and the presence of a significant barrier to adduct formation. ${ }^{8}$ Preliminary isolated reaction studies carried out in this laboratory confirm the upper limit to $k_{1}$ of $<1.5 \times 10^{-33} \mathrm{~cm}^{6}$ molecule ${ }^{-2} \mathrm{~s}^{-1}$ at $298 \mathrm{~K}$, and extend this same limiting value up to $500 \mathrm{~K}$. ${ }^{9}$ These experiments ${ }^{7,9}$ disagree with the results of Gordon et al., ${ }^{10}$ who estimated a room temperature rate constant of $6 \times 10^{-33} \mathrm{~cm}^{6}$ molecule ${ }^{-2} \mathrm{~s}^{-1}$. The $\mathrm{SO}_{2} \cdot \mathrm{H}$ radical is sig- nificant in contexts aside from combustion chemistry. It has been proposed as a reactive intermediate in the high-temperature reduction of $\mathrm{SO}_{2}$ by $\mathrm{H}_{2},{ }^{11}$ and may also be relevant to the atmospheric chemistry of sulfur: Howard and coworkers proposed $\mathrm{SO}_{2} \cdot \mathrm{H}$ as the product of the reaction of $\mathrm{HSO}$ with $\mathrm{NO}_{2}$ at room temperature, and found it reacted readily with $\mathrm{O}_{2}$ to form $\mathrm{HO}_{2}{ }^{12}$

The geometry of the $\mathrm{SO}_{2} \cdot \mathrm{H}$ adduct is uncertain. Two possible structures have the $\mathrm{H}$ atom bonded either to the $\mathrm{S}$ atom, represented here as $\mathrm{HSO}_{2}$, or bonded to an $\mathrm{O}$ atom, represented here as HOSO. The only experimental geometry information to date is from a study by McDowell et al., ${ }^{13}$ who photolyzed a mixture of $\mathrm{HI}$ and $\mathrm{SO}_{2}$ in a frozen $\mathrm{Kr}$ matrix. After repeated annealing, the electron spin resonance (ESR) spectrum of a species identified as $C_{s} \mathrm{HSO}_{2}$ was obtained. This $\mathrm{HSO}_{2}$ adduct has been the subject of two $a b$ initio molecular orbital studies, by Hinchliffe ${ }^{14}$ and by Boyd et al. ${ }^{15}$ The latter work yielded a $\mathrm{H}-\mathrm{SO}_{2}$ bond energy of $142 \mathrm{~kJ} \mathrm{~mol}^{-1}$, a value which is presently recommended for use in modeling atmospheric chemistry ${ }^{16}$ although this bond energy is 60 to $120 \mathrm{~kJ} \mathrm{~mol}^{-1}$ lower than those employed in the combustion studies noted above. Boyd et al. also investigated the possible HOSO adduct and found it to be the more stable structure.

The aim of the present work is to investigate the $\mathrm{HSO}_{2}$ and $H O S O$ adducts by means of $a b$ initio computational methods, in order to obtain information about the likely thermochemistry of reaction (1). For the first time vibrational frequencies are calculated, which should aid attempts to identify matrix-isolated species by IR spectroscopy, and electron correlation is taken into account. The first theoretical study of transition states in the $\mathrm{H}+\mathrm{SO}_{2}$ potential energy surface (PES) is carried out to permit a kinetic analysis of reaction (1) and possible isomerization between the two $\mathrm{SO}_{2} \cdot \mathrm{H}$ structures. 


\section{METHODOLOGY}

Standard computational methods, described in detail elsewhere, ${ }^{17}$ were applied by means of the GAUSSIAN 88 program $^{18}$ implemented on a VAX 6310 computer and GAUSSIAN $90^{19}$ on a Cray Y-MP/832. Stationary points on the PES for $\mathrm{H}+\mathrm{SO}_{2}$ were initially located using the $3-21 \mathrm{G}\left({ }^{*}\right)$ atomic basis set ${ }^{20}$ at the Hartree-Fock (HF) level. This basis set includes $d$-type polarization functions on the $\mathrm{S}$ atom. Spin-restricted $\mathrm{HF}$ was employed for closed-shell $\mathrm{SO}_{2}$, and unrestricted $\mathrm{HF}$ for the open-shell species. We denote these results as $\mathrm{HF} / 3-21 \mathrm{G}\left(^{*}\right)$. Harmonic vibrational frequencies $v_{e}$ were calculated at each stationary point to characterize it as a true minimum or a transition state (TS) with a single imaginary frequency. These $v_{e}$ are scaled by a standard factor of 0.9 to approximate $v_{0}{ }^{17}$ In some cases the geometry was also optimized with the larger $6-31 G^{*}$ basis set, ${ }^{21}$ which includes $d$-type polarization functions on $\mathrm{S}$ and $\mathrm{O}$, to test for any dependence of bond angles and lengths on the size of the atomic basis set.
The geometries of the stationary points were then reoptimized while making a correction for electron correlation by means of Møller-Plesset (MP) second-order perturbation theory for all electrons. Vibrational frequencies were also calculated at this $\mathrm{MP} 2 / 3-21 \mathrm{G}\left({ }^{*}\right)$ level. We verified the stability of the $\mathrm{HF}$ wave function at each stationary point. ${ }^{22}$ Finally, we employed the $6-31 \mathrm{G}^{*}$ basis set to calculate the energy at each MP2/3-21G (*) geometry using MP4 theory (excluding core electrons). Spin-contamination effects on the energies were eliminated by Schlegel's projection meth$\mathrm{od}^{23}$ and the final results are denoted as PMP4/6$31 \mathrm{G}^{*} / / \mathrm{MP} 2 / 3-21 \mathrm{G}\left({ }^{*}\right)$ energies.

\section{RESULTS AND DISCUSSION}

The $a b$ initio geometries, vibrational frequencies, and energies are summarized in Tables I and II and Fig. 1. Three stable minima, corresponding to $\mathrm{H}+\mathrm{SO}_{2}, \mathrm{HOSO}$, and $\mathrm{HSO}_{2}$, and transition states (TS) between them are discussed below. Figure 2 is a diagram of the vibrationally adia-

TABLE I. Ab initio geometries and frequencies for stationary points on the $\mathrm{H}+\mathrm{SO}_{2}$ PES.

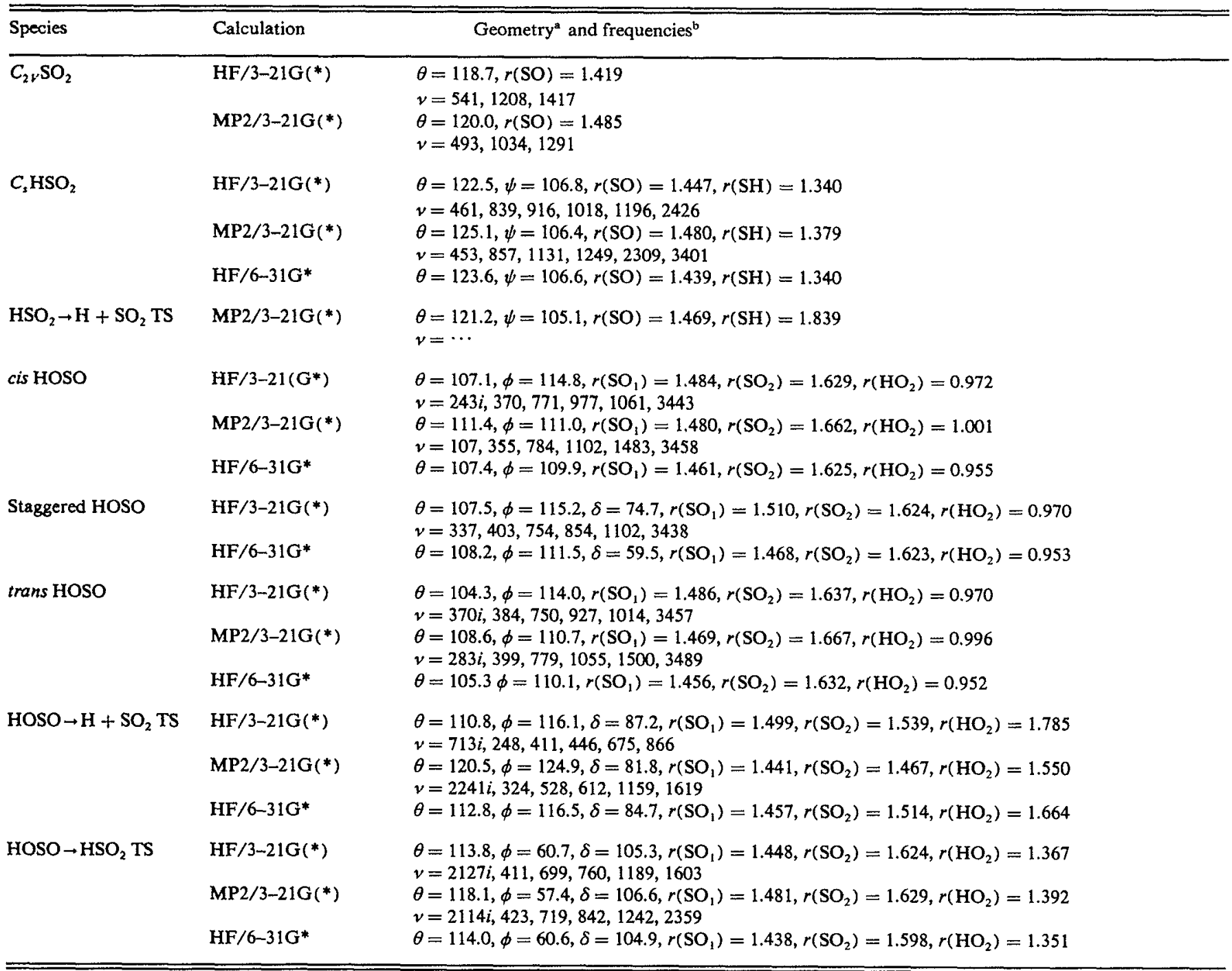

See Fig. 1 for definitions of the coordinates. Angles are in degrees and distances are in $\AA$.

${ }^{b}$ Frequencies are in $\mathrm{cm}^{-1}$ and were calculated only with the $3-21 \mathrm{G}\left(^{*}\right)$ basis set. HF results are scaled by a factor of 0.9 , while MP2 results are unscaled. 
TABLE II. $A b$ initio energies for stationary points on the $\mathrm{H}+\mathrm{SO}_{2} \mathrm{PES}$.

\begin{tabular}{|c|c|c|c|c|}
\hline Species & Calculation & Energy, au & $\left\langle S^{2}\right\rangle$ & $\Delta H_{0}, \mathrm{~kJ} \mathrm{~mol}^{-1 \mathrm{a}}$ \\
\hline $\mathbf{H}$ & $\begin{array}{l}\mathrm{HF} / 3-21 \mathrm{G}(*) \\
\mathrm{HF} / 6-31 \mathrm{G}^{*}\end{array}$ & $\begin{array}{l}-0.4962 \\
-0.4982\end{array}$ & $\begin{array}{l}0.75 \\
0.75\end{array}$ & \\
\hline $\mathrm{OH}$ & $\begin{array}{l}\mathrm{HF} / 3-21 \mathrm{G}\left({ }^{*}\right) \\
\mathrm{MP} 2 / 3-21 \mathrm{G}\left({ }^{*}\right) \\
\text { PMP4/6-31G*//MP2/3-21G(*) }\end{array}$ & $\begin{array}{l}-74.9702 \\
-75.0572 \\
-75.5367\end{array}$ & $\begin{array}{l}0.75 \\
0.75 \\
0.76\end{array}$ & \\
\hline SO & $\begin{array}{l}\mathrm{HF} / 3-21 \mathrm{G}\left(^{*}\right) \\
\mathrm{PMP} 4 / 6-31 \mathrm{G}^{*} / / \mathrm{HF} / 3-21 \mathrm{G}\left(^{*}\right)\end{array}$ & $\begin{array}{l}-470.0747 \\
-472.6361\end{array}$ & $\begin{array}{l}2.03 \\
2.04\end{array}$ & \\
\hline$C_{2 r} \mathrm{SO}_{2}$ & $\begin{array}{l}\mathrm{HF} / 3-21 \mathrm{G}\left(^{*}\right) \\
\mathrm{MP} 2 / 3-21 \mathrm{G}\left({ }^{*}\right) \\
\mathrm{PMP} 4 / 6-31 \mathrm{G}^{*} / / \mathrm{MP} 2 / 3-21 \mathrm{G}\left({ }^{*}\right)\end{array}$ & $\begin{array}{l}-544.5037 \\
-544.9203 \\
-547.7111\end{array}$ & $\begin{array}{l}0 \\
0 \\
0\end{array}$ & \\
\hline$C_{\mathrm{s}} \mathrm{HSO}_{2}$ & $\begin{array}{l}\mathrm{HF} / 3-21 \mathrm{G}\left(^{*}\right) \\
\mathrm{MP} 2 / 3-21 \mathrm{G}^{*} \\
\mathrm{PMP} 4 / 6-31 \mathrm{G}^{*} / / \mathrm{MP} 2 / 3-21 \mathrm{G}\left(^{*}\right)\end{array}$ & $\begin{array}{l}-545.0213 \\
-545.4125 \\
-548.2149\end{array}$ & $\begin{array}{l}0.78 \\
0.78 \\
0.78\end{array}$ & +25 \\
\hline $\mathrm{H}+\mathrm{SO}_{2} \rightarrow \mathrm{HSO}_{2} \mathrm{TS}$ & $\mathrm{MP} 2 / 3-21 \mathrm{G}\left(^{*}\right)$ & -545.3939 & 0.89 & \\
\hline cis HOSO & $\begin{array}{l}\mathrm{HF} / 3-21 \mathrm{G}\left(^{*}\right) \\
\mathrm{MP} 2 / 3-2 \mathrm{IG}\left(^{*}\right) \\
\mathrm{PMP} 4 / 6-31 \mathrm{G}^{*} / / \mathrm{MP} 2 / 3-21 \mathrm{G}\left({ }^{*}\right)\end{array}$ & $\begin{array}{l}-545.0873 \\
-545.4553 \\
-548.2611\end{array}$ & $\begin{array}{l}0.77 \\
0.77 \\
0.77\end{array}$ & -109 \\
\hline Staggered HOSO & $\mathrm{HF} / 3-21 \mathrm{G}\left({ }^{*}\right)$ & -545.0903 & 0.76 & \\
\hline trans HOSO & $\begin{array}{l}\mathrm{HF} / 3-21 \mathrm{G}\left(^{*}\right) \\
\mathrm{MP} 2 / 3-21 \mathrm{G}\left(^{*}\right) \\
\text { PMP4/6-31G*//MP2/3-21G(*) }\end{array}$ & $\begin{array}{l}-545.0785 \\
-545.4444 \\
-548.2537\end{array}$ & $\begin{array}{l}0.76 \\
0.77 \\
0.77\end{array}$ & -90 \\
\hline $\mathrm{HOSO} \rightarrow \mathrm{H}+\mathrm{SO}_{2} \mathrm{TS}$ & $\begin{array}{l}\mathrm{HF} / 3-21 \mathrm{G}\left(^{*}\right) \\
\mathrm{MP} 2 / 3-21 \mathrm{G}\left({ }^{*}\right) \\
\mathrm{PMP} 4 / 6-31 \mathrm{G}^{*} / / \mathrm{MP} 2 / 3-21 \mathrm{G}\left({ }^{*}\right)\end{array}$ & $\begin{array}{l}-544.9986 \\
-545.3616 \\
-548.1763\end{array}$ & $\begin{array}{l}1.44 \\
1.14 \\
1.10\end{array}$ & +95 \\
\hline $\mathrm{HOSO} \rightarrow \mathrm{HSO}_{2} \mathrm{TS}$ & $\begin{array}{l}\mathrm{HF} / 3-21 \mathrm{G}\left({ }^{*}\right) \\
\mathrm{MP} 2 / 3-21 \mathrm{G}\left(^{*}\right) \\
\mathrm{PMP} 4 / 6-31 \mathrm{G}^{*} / / \mathrm{MP} 2 / 3-21 \mathrm{G}\left(^{*}\right)\end{array}$ & $\begin{array}{l}-544.9725 \\
-545.3579 \\
-548.1694\end{array}$ & $\begin{array}{l}0.89 \\
0.85 \\
0.84\end{array}$ & +121 \\
\hline
\end{tabular}

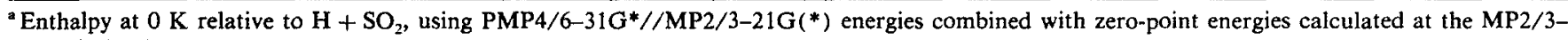
$21 G\left(^{*}\right)$ level.

batic ground-state PES which corresponds to the enthalpy surface at $0 \mathrm{~K}$, i.e., the electronic energy plus zero-point vibrational energy (ZPE). Spin-conservation was assumed, i.e., all stationary points are doublet states. A channel leading to $\mathrm{OH}+\mathrm{SO}$ has also been analyzed.

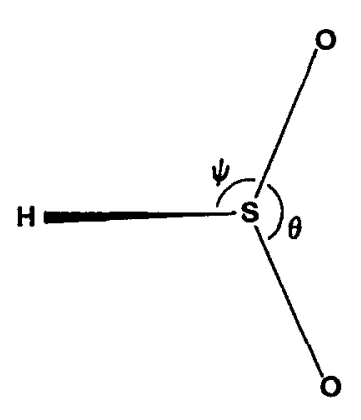

$\mathbf{A}$

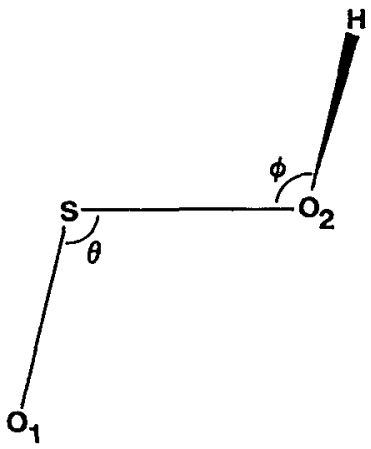

B
FIG. 1. Sketch of molecular structures showing definitions of bond angles for (A) $\mathrm{HSO}_{2}$ and (B) HOSO. The dihedral angle $\mathrm{O}_{1} \mathrm{SO}_{2} \mathrm{H}$ is $\delta$.

\section{A. $\mathrm{SO}_{2}, \mathrm{OH}$, and $\mathrm{SO}$}

It is important to estimate the likely accuracy of these calculations, which we do by comparison with data for experimentally known species. There is reasonable accord between experimental and theoretical geometries for $\mathrm{SO}_{2}$. The calculated bond lengths bracket the experimental value of $1.432 \AA\left(1 \AA=10^{-10} \mathrm{~m}\right):^{24}$ The HF/3-21G(*) distances are about $0.01 \AA$ too small while the higher level MP2/3-21G $\left({ }^{*}\right)$ calculations overestimate $r(\mathrm{SO})$ by about $0.05 \AA$. Similarly, the calculated vibrational frequencies bracket the experimental values of 518, 1151, and 1362 $\mathrm{cm}^{-1} .^{24}$ The scaled HF/3-21G(*) estimates are $7 \%$ too high whereas the (unscaled) MP2/3-21G(*) estimates are $7 \%$ too low. Based on these comparisons, we assign approximate error limits of $\pm 0.05 \AA$ for calculated bond lengths and $\pm 10 \%$ for calculated vibrational frequencies.

The HF/3-21G(*) and MP2/3-21G(*) bond lengths for $\mathrm{OH}$ are 0.985 and $1.006 \AA$, respectively, with frequencies of $3252 \mathrm{~cm}^{-1}$ (after scaling by 0.9 ) and $3378 \mathrm{~cm}^{-1}$. Comparison with the experimental values ${ }^{24}$ of $r_{e}=0.971 \AA$ and $v_{0}=3569 \mathrm{~cm}^{-1}$ shows that the MP2 results overestimate $r_{e}$ 


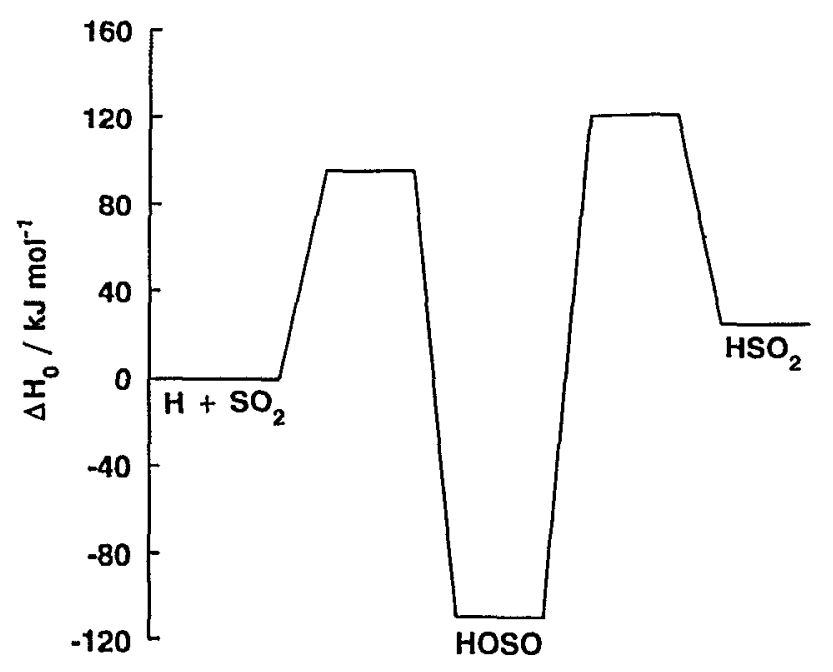

FIG. 2. The potential energy surface for $\mathrm{H}+\mathrm{SO}_{2}$ calculated at the PMP4/6-31G*//MP2/3-21G(*) level and incorporating zero-point vibrational energy calculated at the MP2/3-21G(*) level. The ordinate represents enthalpy relative to $\mathrm{H}+\mathrm{SO}_{2}$ at $0 \mathrm{~K}$.

by $0.04 \AA$ and underestimate $v_{0}$ by $5 \%$, consistent with the error limits proposed. For SO, the HF/3-21G $\left(^{*}\right)$ geometry and scaled frequencies of $r_{e}=1.486 \AA$ and $v_{0}=1129 \mathrm{~cm}^{-1}$ are within $1 \%$ of the experimental values, $1.481 \AA$ and 1136 $\mathrm{cm}^{-1} \cdot{ }^{24}$ However, MP2 calculations do not describe SO satisfactorily: An apparent minimum lies at $r_{e}=1.547 \AA$ where the HF wave function is unstable, which invalidates energy and frequency calculations made with MP methods.

We may also compare the calculated and experimental thermochemistries for $\mathrm{H}+\mathrm{SO}_{2} \rightarrow \mathrm{OH}+\mathrm{SO}$. We employ PMP4/6-31G*//MP2/3-21G (*) data (with the exception of SO, for which PMP4/6-31G*//HF/3-21G $\left(^{*}\right)$ data are chosen) combined with $a b$ initio frequencies to derive the enthalpy change at $0 \mathrm{~K}, \Delta H_{0}=108 \mathrm{~kJ} \mathrm{~mol}^{-1}$. The experimental value is $\Delta H_{0}=123 \mathrm{~kJ} \mathrm{~mol}^{-1,24}$ which suggests we may crudely estimate the uncertainty in $a b$ initio energies as at least $\pm 15 \mathrm{~kJ} \mathrm{~mol}^{-1}$. This energy uncertainty translates into an uncertainty in equilibrium or rate constants of a factor of about 3 at $2000 \mathrm{~K}$, increasing to a factor of 400 at room temperature. Thus all $a b$ initio equilibrium and rate constants must only be regarded as order of magnitude estimates.

\section{B. $\mathrm{HSO}_{2}$ adduct}

The present $\mathrm{HF} / 3-21 \mathrm{G}\left(^{*}\right) C_{s}$ geometry for the $\mathrm{SO}_{2} \cdot \mathrm{H}$ isomer with $\mathrm{H}$ bonded to $\mathrm{S}$ (see Fig. 1 and Table $\mathrm{I}$ ) is similar to that derived with a very small STO-3G (*) atomic basis set by Boyd et al. ${ }^{15}\left[\theta=124.7^{\circ}, r(\mathrm{SO})=1.476 \AA\right.$, $r(\mathrm{SH})=1.362 \AA, \psi=105.1^{\circ} \mathrm{J}$. We also optimized the geometry at the HF/6-31G* level: The results in Table I show there is negligible basis set dependence at the HF level. We note that the structure calculated at the HF level by Hinchliffe $^{14}\left[\theta=132^{\circ}, r(\mathrm{SO})=1.458 \AA, r(\mathrm{SH})=1.336 \AA\right.$, $\left.\psi=105^{\circ}\right]$ has an inconsistently large OSO angle $\theta$. The data in Table I demonstrate that inclusion of electron correlation at the MP2 level has little influence on the geometry.
Our $\mathrm{HF} / 3-21 \mathrm{G}\left({ }^{*}\right)$ calculations also located an asymmetrical $C_{1} \mathrm{HSO}_{2}$ structure, with all real frequencies, and a similar structure was found at the HF/6-31G* level. A TS with a single complex frequency lies between the $C_{8}$ and $C_{1}$ structures. However, attempts to optimize the $C_{1}$ structure at the higher MP2 level led only to the symmetrical $C_{s}$ form, from which we conclude that the $C_{1}$ form does not correspond to a real adduct.

Our best estimate of $\Delta H_{0}$ for the reaction

$$
\mathrm{H}+\mathrm{SO}_{2}+\mathrm{Ar} \rightarrow \mathrm{HSO}_{2}+\mathrm{Ar}
$$

at the PMP4/6-31G*//MP2/3-21G(*) level (including $\mathrm{ZPE}$ ), is $+25 \mathrm{~kJ} \mathrm{~mol}^{-1}$ at $0 \mathrm{~K}$ (see Table II). This predicted endothermicity can be contrasted to the HF/STO-3G $\left({ }^{*}\right)$ estimate of $\Delta H_{0}=-142 \mathrm{~kJ} \mathrm{~mol}^{-1}$ by Boyd et al. ${ }^{15} \mathrm{~A}$ small basis set was employed, and neither ZPE nor electron correlation was included. We therefore believe our result is more reliable. We used our $\Delta H_{0}$ combined with $\mathrm{MP} 2 / 3-21 \mathrm{G}$ ( $\left.^{*}\right)$ structures and frequencies to calculate the equilibrium constant $K_{p}$ for reaction (3) by statistical mechanics. ${ }^{25}$ At 2000 $\mathrm{K}, K_{p}$ is about $10^{-6} \mathrm{~atm}^{-1}$, and decreases with decreasing temperature to about $10^{-8} \mathrm{~atm}^{-1}$ at $298 \mathrm{~K}$. The equilibrium ratio $\left[\mathrm{HSO}_{2}\right]:[\mathrm{H}]$ when $[\mathrm{H}] \ll\left[\mathrm{SO}_{2}\right]$ and $K_{p}$ is small is given by $p\left(\mathrm{SO}_{2}\right) \times K_{p}$, so it is clear that reaction (3) alone cannot be a significant sink for atomic $\mathrm{H}$ either in room temperature experiments or in $\mathrm{SO}_{2}$-seeded flames. We have also estimated the maximum $\mathrm{H}$-atom removal rate possible if $\mathrm{HSO}_{2}$ can react with $\mathrm{H}$ with a rate constant $k_{2}=10^{-10} \mathrm{mo-}$ lecule ${ }^{-1} \mathrm{~cm}^{3} \mathrm{~s}^{-1}$ at $2000 \mathrm{~K}$. The assumption of an initial $[\mathrm{H}]$ of $10^{16} \mathrm{~cm}^{-3}$, and a high $\left[\mathrm{SO}_{2}\right]$ of $2 \times 10^{18} \mathrm{~cm}^{-3}$, leads to a minimum half-life for second-order removal of $\mathrm{H}$ of about $1 \mathrm{~s}$. This is too slow to be significant and we therefore conclude that $\mathrm{HSO}_{2}$ is insufficiently stable to be important in the chemistry of flames.

$\mathrm{HSO}_{2}$ was proposed by McDowell et al. ${ }^{13}$ as the radical species formed by irradiation of an $\mathrm{HI} / \mathrm{SO}_{2}$ mixture in frozen $\mathrm{Kr}$, followed by repeated annealing, and detected by ESR. A very recent study by Fender et al. ${ }^{26}$ also involved irradiation of mixtures of $\mathrm{SO}_{2}$ with $\mathrm{HI}$ or $\mathrm{H}_{2} \mathrm{~S}$, in a solid $\mathrm{Ar}$ matrix. However, these workers identified sulfinic acid $\left(\mathrm{HSO}_{2} \mathrm{H}\right)$ as the sole product on the basis of ir spectroscopy. Presumably, the radical species detected in the earlier matrix-isolation study are formed only in the annealing steps.

\section{Transition state for $\mathrm{HSO}_{2} \rightarrow \mathrm{H}+\mathrm{SO}_{2}$}

The dissociation of $C_{s} \mathrm{HSO}_{2}$ to $\mathrm{H}+\mathrm{SO}_{2}$, reaction ( -3 ), was initially investigated at the $\mathrm{HF} / 3-21 \mathrm{G}\left({ }^{*}\right)$ level. As the S-H distance is increased, the energy rises, but the HF PES is discontinuous and at $r(\mathrm{SH}) \approx 1.9 \AA$, there is a switch to a lower energy $C_{1}$ geometry. A $C_{1}$ TS was located, but in the light of the observation of spurious $C_{1} \mathrm{HSO}_{2}$ (Sec. III B), and because this $C_{1}$ TS could not be confirmed at the MP2 level, we believe the TS may also be an artifact. MP2/3-21G $\left(^{*}\right)$ calculations located a possible $C_{s}$ TS with structure $\theta=119.4^{\circ}, \quad \psi=105.1^{\circ}, \quad r(\mathrm{SO})=1.469 \quad \AA$, $r(\mathrm{SH})=1.839 \AA$. However, vibrational frequencies could not be obtained because of HF instability. ${ }^{22}$ This possible TS has an electronic energy $49 \mathrm{~kJ} \mathrm{~mol}^{-1}$ higher than $C_{s} \mathrm{HSO}_{2}$ 
at the MP2/3-21G(*) level, but changes in ZPE must also be considered. During dissociation, $39 \mathrm{~kJ} \mathrm{~mol}^{-1}$ of $\mathrm{ZPE}$ are lost, which means that the energy barrier in the vibrationally adiabatic PES may be small. Even if the barrier were as much as $40 \mathrm{~kJ} \mathrm{~mol}^{-1}$, a likely rate constant for room temperature high-pressure unimolecular dissociation, on the assumption of a typical preexponential factor of $10^{13} \mathrm{~s}^{-1},{ }^{27}$ is about $10^{6}$ $\mathrm{s}^{-1}$. Concentrations of the $\mathrm{HSO}_{2}$ radical above equilibrium will therefore be very short lived in the gas phase.

\section{HOSO adduct}

We have found a single stable minimum at the $\mathrm{HF} / 3$ $21 \mathrm{G}\left(^{*}\right)$ level where the $\mathrm{H}$ atom is bonded to an $\mathrm{O}$ atom and twisted out of the $\mathrm{SO}_{2}$ plane (see Table I). $\mathrm{HF} / 6-31 \mathrm{G}^{*}$ calculations yield a similar structure and confirm the absence of basis-set dependence. This staggered configuration is similar to that described by Boyd et al. ${ }^{15}$ The planar cis and trans HOSO conformers are both saddlepoints at the HF/3$21 \mathrm{G}\left({ }^{*}\right)$ level, with energies (including ZPE) of 29 and 6 $\mathrm{kJ} \mathrm{mol}^{-1}$ above the staggered form. Again, $\mathrm{HF} / 6-31 \mathrm{G}^{*}$ calculations are in accord and also show these conformations to be saddlepoints. By contrast, MP2/3-21G(*) calculations indicate that the cis structure is a stable minimum, the trans structure remains a TS and there is no staggered stationary point. The cis form may be stabilized by intramolecular hydrogen bonding. The energy barrier, including changes in ZPE, to rotation of $\mathrm{OH}$ about the $\mathrm{S}-\mathrm{O}$ bond is 19 $\mathrm{kJ} \mathrm{mol}^{-1}$ at the PMP4/6-31G*//MP2/3-21G(*) level (see Table II). The vibrational frequency of the mode of $c i s$ HOSO which corresponds to motion of the $\mathrm{H}$ atom out of the $\mathrm{SO}_{2}$ plane is low, about $100 \mathrm{~cm}^{-1}$, which is another indication of easy internal rotation. This torsional frequency, coupled with the reduced moment of inertia for internal rotation of $1.46 \times 10^{-47} \mathrm{~kg} \mathrm{~m}^{2}$, corresponds to a rotational barrier of $6 \mathrm{~kJ} \mathrm{~mol}^{-1}$ if a sinusoidal potential is assumed. ${ }^{28}$ These two measures are consistent with a small rotational barrier of around $10 \mathrm{~kJ} \mathrm{~mol}^{-1}$. We have therefore decided to replace the slightly hindered internal rotor with a free rotor for the purposes of thermodynamic calculations, which should be a good approximation at elevated temperatures.

Our best estimate (Table II) of the H-OSO bond energy is $D_{0}=109 \mathrm{~kJ} \mathrm{~mol}^{-1}$. By chance, this is close to the $D_{0}$ recommended by Atkinson et al. for $\mathrm{H}-\mathrm{SO}_{2}{ }^{16}{ }^{16} \mathrm{We}$ have calculated $K_{c}$ for the reaction

$$
\mathrm{H}+\mathrm{SO}_{2}+\mathrm{Ar} \rightarrow \mathrm{HOSO}+\mathrm{Ar}
$$

from 298 to $2000 \mathrm{~K}$, and fit the results to yield $K_{c}=1.1 \times 10^{-23} \exp \left(1.35 \times 10^{4} \mathrm{~K} / \mathrm{T}\right)$ molecule ${ }^{-1} \mathrm{~cm}^{3}$. This implies values of $K_{\rho}$ for reaction (4) at 298 and $2000 \mathrm{~K}$ of $1.2 \times 10^{16}$ and $3.9 \times 10^{-2} \mathrm{~atm}^{-1}$, respectively, so that HOSO is sufficiently stable to be an important sink for atomic $\mathrm{H}$ in flames.

Three potential unimolecular decomposition pathways for the HOSO adduct are considered in the following sections: (i) dissociation back to $\mathrm{H}+\mathrm{SO}_{2}$, (ii) rearrangement to $\mathrm{HSO}_{2}$, and (iii) dissociation to $\mathrm{OH}+\mathrm{SO}$.

\section{E. Transition state for $\mathrm{HOSO} \rightarrow \mathrm{H}+\mathrm{SO}_{2}$}

The transition state for dissociation of HOSO to $\mathrm{H}+\mathrm{SO}_{2}$, the most exothermic possible dissociation products considered, has been characterized at the HF and MP2 levels of calculation. The results (Table I) show that the MP2 calculations yield a tighter TS, with a shorter $\mathrm{O}-\mathrm{H}$ distance than at the HF level and with higher frequencies. The MP2 results also indicate that the OSO moiety has relaxed to essentially the equilibrium $\mathrm{SO}_{2}$ geometry. While small barriers to association are typical for recombination of a radical with a closed shell molecule, ${ }^{29}$ PMP4/6$31 \mathrm{G} * / / \mathrm{MP} 2 / 3-21 \mathrm{G}\left(^{*}\right)$ calculations indicate a remarkably large energy barrier for reaction (4) of $95 \mathrm{~kJ} \mathrm{~mol}^{-1}$ relative to $\mathrm{H}+\mathrm{SO}_{2}$. This TS shows a strong variation of the $\mathrm{O}-\mathrm{H}$ distance with the level of calculation, decreasing from 1.785 $\AA$ at the $\mathrm{HF} / 3-21 \mathrm{G}\left({ }^{*}\right)$ level to $1.550 \AA$ at the $\mathrm{MP} 2 / 3-$ $21 \mathrm{G}\left({ }^{*}\right)$ level. This uncertainty in $r(\mathrm{OH})$ could lead to significant error in the energy of the TS because the PES curves steeply there, as reflected by the complex frequency of the order of $1000 i \mathrm{~cm}^{-1}$. For example, calculation of the PMP4/6-31G* energy at the HF rather than MP2 geometry lowers the barrier by $36 \mathrm{~kJ} \mathrm{~mol}^{-1}$. We therefore checked the TS geometry at higher levels of theory to see whether the long or short $\mathrm{O}-\mathrm{H}$ partial bond is supported. The HF/6$31 \mathrm{G}^{*}$ geometry has $r(\mathrm{OH})=1.664 \AA$ (Table I) while the complete $\mathrm{MP} 2 / 6-31 \mathrm{G}^{*}$ geometry is $r\left(\mathrm{SO}_{1}\right)=1.441 \AA$, $r\left(\mathrm{SO}_{2}\right)=1.460 \AA, \quad r\left(\mathrm{O}_{2} \mathrm{H}\right)=1.507 \AA, \quad \theta=120.2^{\circ}$, $\phi=125.2^{\circ}$, and $\delta=78.2^{\circ}$ (see Fig. 1). These results suggest that the MP2/3-21G(*) geometry is indeed reliable.

We have analyzed the kinetics of unimolecular dissociation by means of Rice-Ramsberger-Kassel-Marcus (RRKM) theory, following the procedures described by Gilbert and co-workers. ${ }^{29,30}$ The two rotations, of both HOSO and the TS, with the smallest moments of inertia were taken as inactive (whose energy is unavailable for crossing the potential barrier) and in each case the third rotation was taken to be active. The Lennard-Jones collision rate between HOSO and Ar bath gas was estimated by means of the Lennard-Jones parameters for $\mathrm{Ar}$ and $\mathrm{SO}_{2},{ }^{31}$ to yield $\sigma_{\mathrm{L} J}=3.854 \AA$ and $\epsilon_{\mathrm{LJ}}=177 \mathrm{~K}$. A weak-collision "exponential down" model for energy transfer between excited HOSO and Ar was assumed. ${ }^{29}$ This leads to a calculated collision efficiency $\beta_{c}$ of 0.48 at $298 \mathrm{~K}$, decreasing to 0.036 at $2000 \mathrm{~K}$. These values are in line with typical $\beta$ values at room and flame temperatures. ${ }^{32} \mathrm{We}$ used the UNIMOL pro$\mathrm{gram}^{30}$ to calculate falloff curves for reaction $(-4)$ at 298 and $2000 \mathrm{~K}$, and the results are drawn in Fig. 3. The reaction will be in the third-order region under most flame conditions, but falloff behavior would, in principle, be evident at $298 \mathrm{~K}$ at pressures of the order of 100 Torr. As shown below, the reaction will, however, be too slow to measure at room tions, but falloff behavior would, in principle, be evident at $298 \mathrm{~K}$ at pressures of the order of 100 Torr. As shown below, the reaction will, however, be too slow to measure at room temperature.

We have also calculated the low-pressure second-order dissociation rate constant $k_{-4}$ as a function of temperature. The dissociation rate will be negligible for $T<700 \mathrm{~K}$. Because the dissociation step involves motion of an $\mathrm{H}$ atom 


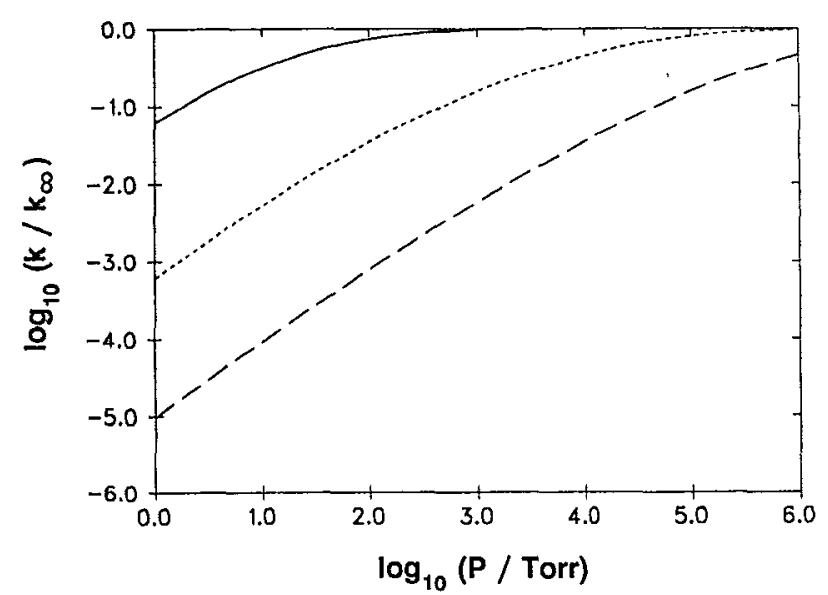

FIG. 3. Falloff curves for $\mathrm{H}+\mathrm{SO}_{2}+\mathrm{Ar} \rightleftharpoons \mathrm{HOSO}+\mathrm{Ar}$ at (i) $298 \mathrm{~K}$, solid line; (ii) $1000 \mathrm{~K}$, short dashes; (iii) $2000 \mathrm{~K}$, long dashes.

over a potential barrier the possibility of quantum mechanical tunneling exists. We have crudely estimated a tunneling correction factor by fitting an Eckart potential ${ }^{3.3}$ to the vibrationally adiabatic PES, as employed previously to analyze the decomposition of $\mathrm{HNNO},{ }^{34}$ to derive the tunneling-corrected rate constant plotted on Fig. 4. The correction factor decreases from $4 \times 10^{4}$ at $298 \mathrm{~K}$, through 2.8 at $700 \mathrm{~K}$ to 1.1 at $2000 \mathrm{~K}$. The final results for $T=700$ to $2000 \mathrm{~K}$ can be summarized by $k_{-4} \approx 2.5 \times 10^{-9} \exp (-19800 \mathrm{~K} / \mathrm{T})$ $\mathrm{cm}^{3}$ molecule ${ }^{-1} \mathrm{~s}^{-1}$.

The equilibrium constant for reaction (4) (see Sec. III $D$ ) is used to derive the third-order rate constant for $\mathrm{H}+\mathrm{SO}_{2}$ recombination, corrected for tunneling and plotted on Fig. 5. For $T \geqslant 700 \mathrm{~K}$ an approximate expression is $k_{4} \approx 3.1 \times 10^{-32} \exp (-6300 \mathrm{~K} / \mathrm{T}) \mathrm{cm}^{6}$ molecule ${ }^{-2} \mathrm{~s}^{-1}$. An interesting feature is that the activation energy for recombination is about $52 \mathrm{~kJ} \mathrm{~mol}^{-1}$, which is considerably smaller than the energy barrier of $95 \mathrm{~kJ} \mathrm{~mol}^{-1}$. This reflects

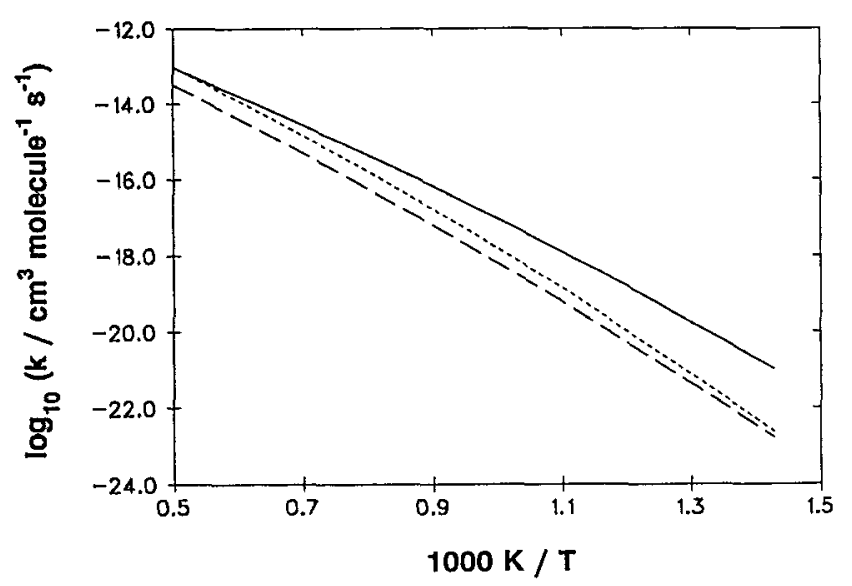

FIG. 4. Arrhenius plot of low-pressure limiting rate constants for $\mathrm{HOSO}+\mathrm{Ar}$ reacting to (i) $\mathrm{H}+\mathrm{SO}_{2}\left(k_{-4}\right)$, solid line; (ii) $\mathrm{HSO}_{2}\left(k_{5}\right)$, long dashes; (iii) $\mathrm{OH}+\mathrm{SO}\left(k_{6}\right)$, short dashes.

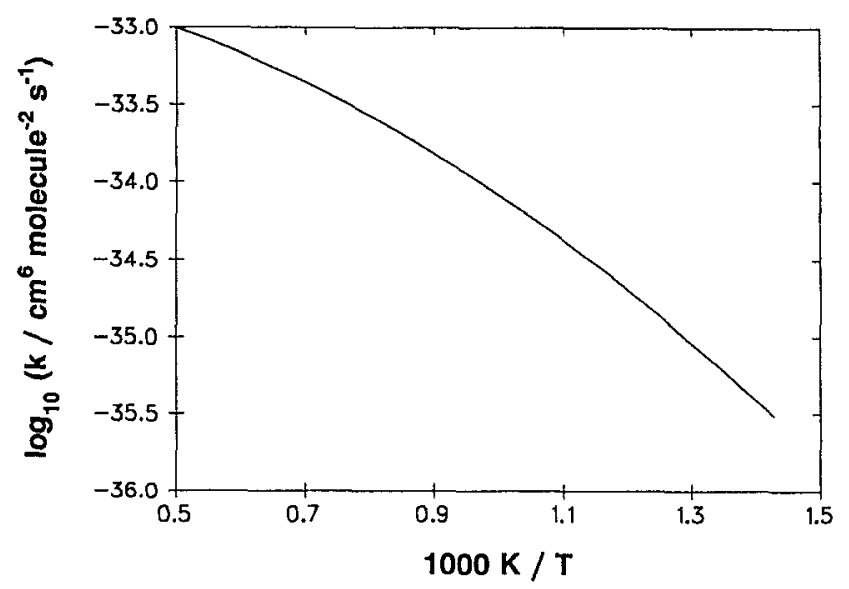

FIG. 5. Arrhenius plot of third-order rate constant $k_{4}$ for $\mathrm{H}+\mathrm{SO}_{2}+\mathrm{Ar}$ $\rightarrow \mathrm{HOSO}+\mathrm{Ar}$.

two factors: At low temperatures tunneling enhances reactivity, and more importantly, at high temperatures collisional stabilization of nascent excited HOSO is inefficient and reduces $k_{4}$. This latter effect also causes the non-Arrhenius curvature of Fig. 5 . At $298 \mathrm{~K}, k_{4}$ is predicted to be negligibly slow $\left(k_{4} \approx 10^{-40} \mathrm{~cm}^{6}\right.$ molecule $\left.{ }^{-2} \mathrm{~s}^{-1}\right)$. This is consistent with the lack of reaction noted by Fair and Thrush who used a fast-flow technique, ${ }^{7}$ and the absence of reaction seen in our own laboratory where flash photolysis/resonance fluorescence experiments were performed. ${ }^{9}$ Both studies employed Ar bath gas and suggest $k_{4}<1.5 \times 10^{-33} \mathrm{~cm}^{6}$ molecule ${ }^{-2} \mathrm{~s}^{-1}$ at room temperature. Our experiments also give an upper limit to $k_{4}$ of $<1.5 \times 10^{-33} \mathrm{~cm}^{6}$ molecule ${ }^{-2} \mathrm{~s}^{-1}$ at $500 \mathrm{~K}$, consistent with a predicted $k_{4}$ there of $\approx 10^{-38}$ $\mathrm{cm}^{6}$ molecule ${ }^{-2} \mathrm{~s}^{-1}$. The presence of a large energy barrier thus dramatically slows $\mathrm{H}+\mathrm{SO}_{2}$ recombination. This reaction can be contrasted to the recombination of valence isoelectronic $\mathrm{Na}$ with $\mathrm{SO}_{2}$, which has little or no barrier and for which the third-order rate constant is about $3 \times 10^{-29}$ $\mathrm{cm}^{6}$ molecule ${ }^{-2} \mathrm{~s}^{-1}$ at $T \approx 800 \mathrm{~K}^{35}$

We now compare our results with combustion studies. Flame models do not discriminate between formation of $\mathrm{HOSO}$ and $\mathrm{HSO}_{2}$ and yield $k_{1}=k_{3}+k_{4}$. Because of the unfavorable thermochemistry predicted for reaction (3) (see Sec. III B), we assume $k_{1} \approx k_{4}$. For $T \approx 2000 \mathrm{~K}$ Baulch et al. recommend $k_{4}=1.4 \times 10^{-32} \mathrm{~cm}^{6}$ molecule ${ }^{-2} \mathrm{~s}^{-1}$ with error limits of at least $50 \%,{ }^{36}$ based on combustion studies. This value of $k_{4}$ is about an order of magnitude greater than the $a b$ initio result $k_{4} \approx 10^{-33} \mathrm{~cm}^{6}$ molecule ${ }^{-2} \mathrm{~s}^{-1}$ at $2000 \mathrm{~K}$. One reason for this discrepancy is that recombination rate constants are dependent on the bath gas. An example is the reaction $\mathrm{O}+\mathrm{SO}_{2}+\mathrm{M} \rightarrow \mathrm{SO}_{3}+\mathrm{M}$, where the rate constant for $\mathrm{M}=\mathrm{SO}_{2}$ is about ten times greater than for $\mathrm{M}=\mathrm{Ar} \cdot{ }^{37}$ The presence of efficient quenching species such as $\mathrm{SO}_{2}$ and $\mathrm{H}_{2} \mathrm{O}$ in flames may increase $k_{4}$ above the value calculated here for $\mathrm{M}=\mathrm{Ar}$. It is also possible that the ab initio barrier to reaction (4) may be significantly overestimated, or that the interpretation of the flame results, which rests partly on questionable $\mathrm{H}-\mathrm{OSO}$ bond energies, may need to be revised. 


\section{F. Transition state for $\mathrm{HOSO} \rightarrow \mathrm{HSO}_{2}$}

A second possible unimolecular channel for HOSO is isomerization to the $\mathrm{HSO}_{2}$ structure,

$$
\mathrm{HOSO}+\mathrm{Ar} \rightarrow \mathrm{HSO}_{2}+\mathrm{Ar} \text {. }
$$

As noted in Sec. III C, $\mathrm{HSO}_{2}$ will, in turn, rapidly decompose to $\mathrm{H}+\mathrm{SO}_{2}$, so reaction (5) is effectively an alternate pathway to $\mathrm{H}+\mathrm{SO}_{2}$ at flame temperatures. Comparison of structures obtained with the $3-21 G\left(^{*}\right)$ and $6-31 G^{*}$ basis sets show there is no significant basis set dependence at the HF level (Table I). The MP2/3-21G(*) transition state parameters summarized in Table $I$ together with the PMP4/6-31G*//MP2/3-21G (*) energy (Table II) were employed to analyze the kinetics for reaction (5) in the same way as outlined in Sec. III E. The energy barrier, relative to HOSO, is $230 \mathrm{~kJ} \mathrm{~mol}^{-1}$ which is similar to that predicted for the isomerization of HSO to HOS. ${ }^{38}$ The tunneling-corrected results are plotted on Fig. 4. The predicted $k_{5}$ is $4.6 \times 10^{-9} \exp (-23100 \mathrm{~K} / \mathrm{T}) \mathrm{cm}^{3}$ molecule $^{-1} \mathrm{~s}^{-1}$ over the range 700 to $2000 \mathrm{~K}$. For $T>1000 \mathrm{~K}, k_{5}$ is about a third of $k_{-4}$, because of the greater barrier to isomerization. Thus $k_{5}$ is not large enough to change the order of magnitude estimates of the kinetics for $\mathrm{H}+\mathrm{SO}_{2} \rightleftarrows \mathrm{HOSO}$ significantly.

\section{G. Transition state for $\mathrm{HOSO} \rightarrow \mathrm{OH}+\mathrm{SO}$}

A preliminary search of the PES for the process

$$
\mathrm{HOSO}+\mathrm{Ar} \rightarrow \mathrm{OH}+\mathrm{SO}+\mathrm{Ar}
$$

at the $\mathrm{HF} / 3-21 \mathrm{G}\left({ }^{*}\right)$ level found no evidence of an energy barrier beyond the reaction endothermicity. In order to analyze the kinetics of reaction (6) for $T \geqslant 700 \mathrm{~K}$, we applied canonical variational transition state theory to locate an approximate TS. ${ }^{29}$ We considered the OS-OH bond to correspond to the reaction coordinate $r$, and assumed free rotation about this bond for all values of $r$ (see Sec. III D). A crude force constant for small displacements along the reaction coordinate was obtained by slightly varying $r$ from the optimized value in $\mathrm{HOSO}$ at the MP2 level, and recalculating the MP2 energy while all other geometry parameters were held constant. A Morse potential was then fit as a function of $r$, with parameters $D_{e}=123 \mathrm{~kJ} \mathrm{~mol}^{-1}$ and $\beta=3.05 \AA^{-1}$. The $\mathrm{O}-\mathrm{H}$ and $\mathrm{S}-\mathrm{O}$ vibrational frequencies in the TS were taken to be equal to those for SO and OH (Sec. III A). Rotational constants for the rocking motions of the $\mathrm{SO}$ and $\mathrm{OH}$ fragments in the TS were estimated as 16.8 and $0.48 \mathrm{~cm}^{-1} .^{30}$ Trial and error was employed to find the value of $r$, about 3.5 $\AA$, which minimized the high-pressure unimolecular decomposition rate constant at each $T$. Calculations at $T=1400 \mathrm{~K}$ show that for $\mathrm{P}<1000$ Torr, $k_{6}$ is within $10 \%$ or less of the low-pressure limit, consistent with falloff curves for $k_{-4}$ (Fig. 3). The temperature dependence of $k_{6}$ is plotted on Fig. 4 , and can be summarized as $k_{6}=2.3 \times 10^{-8}$ $\exp (-23900 \mathrm{~K} / \mathrm{T}) \mathrm{cm}^{3}$ molecule $\mathrm{e}^{-1} \mathrm{~s}^{-1}$ for $T \geqslant 700 \mathrm{~K}$. From 1000 to $2000 \mathrm{~K}, k_{6}$ varies from about 0.1 to 1 times $k_{-4}$, and this channel may need to be considered in combustion models.

The absence of any barrier to reaction (6) suggests that a possible pathway for the recombination reaction of $\mathrm{OH}$ with SO is via initial formation of HOSO. This recombina- tion rate constant has been measured at room temperature to be about $9 \times 10^{-11} \mathrm{~cm}^{3}$ molecule ${ }^{-1} \mathrm{~s}^{-1},,^{39}$ which is close to gas kinetic and therefore consistent with the absence of a barrier. Products have yet to be determined experimentally; The assumed products of $\mathrm{H}+\mathrm{SO}_{2}$ might be formed directly or by fragmentation of excited HOSO as part of a chemical activation mechanism.

\section{CONCLUSIONS}

Two adducts can be formed by recombination of $\mathrm{H}$ with $\mathrm{SO}_{2}$. HOSO is predicted to be the more stable, with an $\mathrm{HOSO}$ bond energy of $190 \mathrm{~kJ} \mathrm{~mol}^{-1}$, whereas $\mathrm{HSO}_{2}$ is endothermic by $25 \mathrm{~kJ} \mathrm{~mol}^{-1}$ with respect to $\mathrm{H}+\mathrm{SO}_{2}$. Vibrational frequencies of the adducts have been calculated, which should aid in their identification by infrared spectroscopy. Several conformers of HOSO were examined: Inclusion of electron correlation suggests that only planar cis HOSO is a stable species. Investigation of the transition state between $\mathrm{HOSO}$ and $\mathrm{H}+\mathrm{SO}_{2}$ suggests the presence of a large barrier, which is consistent with the lack of reaction noted experimentally at $T \leqslant 500 \mathrm{~K}$. The $\mathrm{H}+\mathrm{SO}_{2}+\mathrm{Ar}$ recombination rate constant is estimated to be about $10^{-33} \mathrm{~cm}^{6}$ molecule ${ }^{-2} \mathrm{~s}^{-1}$ at $2000 \mathrm{~K}$, about an order of magnitude smaller than estimated from combustion studies. These studies may need revision in the light of the new thermochemistry calculated here, or else the barrier to recombination may be smaller than predicted. Two other unimolecular channels for $\mathrm{HOSO}$, isomerization to $\mathrm{HSO}_{2}$ and decomposition to $\mathrm{SO}+\mathrm{OH}$, have also been characterized. The results suggest that a possible reaction mechanism for the reaction of $\mathrm{OH}$ with SO may be via an excited HOSO intermediate.

\section{ACKNOWLEDGMENTS}

We are grateful for support from the R. A. Welch Foundation (Grant No. B-1174) and from UNT Organized Research Funds. Computer time was provided by UNT and the NSF Pittsburgh Supercomputing Center, through Grant No. CHE900059P.

'M. R. Zacharia and O. I. Smith, Combust. Flame 69, 125 (1987).

'A. S. Kallend, Trans. Faraday Soc. 63, 2442 (1967).

${ }^{3}$ C. J. Halstead and D. R. Jenkins, Trans. Faraday Soc. 65, 3013 (1969).

${ }^{4}$ R. A. Drurie, G. M. Johnson, and M. Y. Smith, Combust. Flame 17, 197 (1971).

sC. F. Cullis and M. F. R. Mulcahy, Combust. Flame 18, 225 (1972).

${ }^{6}$ A. S. Kallend, Combust. Flame 19, 227 (1972).

${ }^{7}$ R. W. Fair and B. A. Thrush, Trans. Faraday Soc. 65, 1550 (1969).

${ }^{8} \mathrm{~K}$. Schofield, J. Phys. Chem. Ref. Data 2, 25 (1973).

'Y, Shi, L. Ding, and P. Marshall (unpublished work). H atoms were generated by flash photolysis of $\mathrm{NH}_{3}$ in the presence of excess $\mathrm{SO}_{2}$ in an $\mathrm{Ar}$ bath gas, and monitored by time-resolved atomic resonance fluorescence.

${ }^{10}$ E. B. Gordon, B. I. Ivanov, A. P. Perminov, and V. E. Balalaev, Chem. Phys. 35, 79 (1978).

"V. A. Arutyunov, V. I. Vedeneev, V. A. Ushakov, and V. V. Shumova, Kinet. Catal. 31, 6 (1990).

${ }^{12}$ E. R. Lovejoy, N. S. Wang, and C. J. Howard, J. Phys. Chem. 91,5749 (1987).

${ }^{13}$ C. A. McDowell, F. G. Herring, and J. C. Tait, J. Chem. Phys. 63, 3278 (1975).

${ }^{14}$ A. Hinchliffe, J. Mol. Struct. 71, 349 (1981).

${ }^{15}$ R. J. Boyd, A. Gupta, R. F. Langler, S. P. Lownie, and J. A. Pincock, Can. J. Chem. 58, 331 (1980).

${ }^{16}$ R. Atkinson, D. L. Baulch, R. A. Cox, R. F. Hampson, Jr., J. A. Kerr, and 
J. Troe, J. Phys. Chem. Ref. Data 18, 881 (1989).

${ }^{17}$ W. J. Hehre, L. Radom, P. v. R. Schleyer, and J. A. Pople, Ab Initio Molecular Orbital Theory (Wiley, New York, 1986).

${ }^{11}$ M. J. Frisch, M. Head-Gordon, H. B. Schlegel, K. Raghavachari, J. S. Binkley, C. Gonzalez, D. J. Defrees, D. J. Fox, R. A. Whiteside, R. Seeger, C. F. Melius, J. Baker, R. L. Martin, L. R. Kahn, J. J. P. Stewart, E. M. Fluder, S. Topiol, and J. A. Pople, Gaussian 88 (Gaussian, Pittsburgh, 1988).

${ }^{14}$ M. J. Frisch, M. Head-Gordon, G. W. Trucks, J. B. Foresman, H. B. Schlegel, K. Raghavachari, M. A. Robb, J. S. Binkley, C. Gonzalez, D. J. Defrees, D. J. Fox, R. A. Whiteside, R. Seeger, C. F. Melius, J. Baker, R. L. Martin, L. R. Kahn, J. J. P. Stewart, S. Topiol, and J. A. Pople, GAUSSIAN 90 (Gaussian, Pittsburgh, 1990).

20W. J. Pietro, M. M. Francl, W. J. Hehre, D. J. deFrees, J. A. Pople, and J. S. Binkley, J. Am. Chem. Soc. 104, 5039 (1982)

'M. M. Francl, W. J. Pietro, W. J. Hehre, J. S. Binkley, M. S. Gordon, D. J. DeFrees, and J. A. Pople, J. Chem. Phys. 77, 3654 (1982).

:R. Seeger and J. A. Pople, J. Chem. Phys. 66, 3045 (1977).

"H. B. Schlegel, J. Chem. Phys. 84, 4530 (1986).

${ }^{24}$ M. W. Chase, Jr., C. A. Davies, J. R. Downey, Jr., D. J. Frurip, R. A. McDonald, and A. N. Syverud, JANAF Thermochemical Tables, 3rd ed. [J, Phys. Chem. Ref. Data 14, Suppl. No. 1 (1985)].

${ }^{25} \mathrm{G}$. N. Lewis and M. Randall, Thermodynamics, 2nd ed., revised by K. S. Pitzer and L. Brewer (McGraw-Hill, New York, 1961) Ch. 27.

${ }^{2 h}$ M. A. Fender, Y. M. Sayed, and F. T. Prochaska, J. Phys. Chem. 95, 2811 (1991).
${ }^{27}$ S. W. Benson, Thermochemical Kinetics (Wiley-Interscience, New York, 1976), ch. 3.

${ }^{2 x}$ K. S. Pitzer and W. D. Gwinn, J. Chem. Phys. 10, 428 (1942).

${ }^{29}$ R. G. Gilbert and S. C. Smith, Theory of Unimolecular and Recombination Reactions (Blackwell, Oxford, 1990).

${ }^{30}$ R. G. Gilbert, M. J. T. Jordan, and S. C. Smith, UNIMOL program, 1990 (see Ref. 29).

${ }^{31}$ R. C. Reid and T. K. Sherwood, The Properties of Gases and Liquids (McGraw-Hill, New York, 1958).

${ }^{32}$ W. C. Gardiner, Jr., and J. Troe, in Combusion Chemistry, edited by W. C. Gardiner, Jr. (Springer-Verlag, New York, 1984), Ch. 4.

${ }^{33}$ H. S. Johnston, Gas Phase Reaction Rate Theory (Ronald, New York, 1966), Ch. 2.

${ }^{34}$ P. Marshall, A. Fontijn, and C. F. Melius, J. Chem. Phys. 86, 5540 (1987).

${ }^{35}$ Y. Shi and P. Marshall, J. Phys. Chem. 95, 1654 (1991).

${ }^{36}$ D. L. Baulch, D. D. Drysdale, J. Duxbury, and S. J. Grant, Evaluated Kinetic Data for High Temperature Reactions, Vol. 3 (Butterworths, London, 1976).

${ }^{37}$ D. L. Singleton and R. J. Cvetanovic, J. Phys. Chem. Ref. Data 17, 1377 (1988).

${ }^{38}$ P. L. M. Plummer, J. Chem. Phys. 92, 6627 (1990).

${ }^{39}$ W. B. DeMore, M. J. Molina, S. P. Sander, D. M. Golden, R. F. Hampson, M. J. Kurylo, C. J. Howard, and A. R. Ravishankara, Chemical Kinetics and Photochemical Data for Use in Stratospheric Modeling. Evaluation No. 8 (Jet Propulsion Laboratory, Pasadena, 1987). 